UDK 783(497.4)»18《

821.112.2-6Foerster:Witt

Aleš Nagode (Ljubljana)

\title{
Začetki slovenskega cecilijanstva v luči korespondence med Antonom Foersterjem in Franzom Xaverjem Wittom
}

\section{The Beginnings of the Cecilian Movement in Slovenia as Witnessed by the Correspondence between Anton Foerster and Franz Xaver Witt}

Ključne besede: katoliška cerkvena glasba, Slovenija, cecilijanstvo, Anton Foerster

\section{IZVLEČEK}

Skladatelj in cerkveni glasbenik Anton Foerster je $\mathrm{v}$ dosedanjih glasbeno zgodovinopisnih obravnavah veljal za osrednjo osebnost in idejnega vodjo cecilijanskega gibanja na Slovenskem. Novoodkrita korespondenca z Francem X. Wittom, vodjo nemškega ACV in urednika revije Musica sacra, pa ga postavlja v drugačno luč. V pismih izraženi Foersterjevi pogledi na cerkveno glasbo in konkretne osebnosti slovenske cerkvene glasbe se močno oddaljeval od stališč, ki jih je za svoje propagiralo društvo. To ne prinese le bistvenih sprememb v naše poznavanje Foersterjevih umetniških nazorov, temveč ključno spreminja naše vedenje o oblikovanju idejne osnove in konkretnem delovanju Cecilijinega društva za Ljubljansko škofijo.
Keywords: catholic church music, Slovenia, the Cecilian movement, Anton Foerster

\section{Abstract}

Slovenian composer and church musician, Anton Foerster, was until recently considered to be a key figure and ideological leader of the Slovenian Cecilian movement. Newly discovered correspondence between the leader of the German Cecilian movement and editor of the review Musica sacra has cast new light on his role in the Slovenian Cecilian movement. The radical views expressed in his letters differ significantly from the official position of the Cecilian Society. The author of the present article attempts to investigate the consequences of this fact for our understanding of the emergence and development of the Cecilian movement in Slovenia.

Življenje in delo Antona Foersterja je bilo do sedaj predmet opazovanja številnih znanstvenih prispevkov. Njihovi avtorji so se bolj ali manj poglobljeno posvečali različnim segmentom njegove raznolike dejavnosti, le redki pa so se dotaknili temeljnega problema slovenskega zgodovinopisnega ukvarjanja z osebnostjo in delovanjem Antona 
Foersterja. Njegova podoba v zavesti današnje slovenske znanstvene in kulturne javnosti je namreč nekako razcepljena. Na eni strani se nam zarisuje kot lik glasbenika, ki je v ključnem trenutku narodnega preporoda stopil v slovenski kulturni prostor in - kot za tukajšnje razmere izjemno usposobljen ustvarjalec, izvajalec in pedagog - ključno prispeval k vzpostavitvi slovenske glasbene ustvarjalnosti kot prepoznavnega dela kulturne dejavnosti v tem delu avstrijskih dednih dežel. Za dobro desetletje in pol je postal osrednje orodje slovenskih glasbenokulturnih prizadevanj, čigar odsotnost je največkrat pomenila kvalitativni upad ali celo zamrtje mnogih osrednjih preporodnih glasbenih dejavnosti. Na drugi strani pa ga slovenska glasbena zgodovina postavlja na mesto osrednje osebnosti cecilijanskega gibanja, ki si je z zagovarjanjem politično nekorektnih načel nakopalo ostro nasprotovanje precejšnjega dela sodobne slovenske kulturne javnosti, ki - kot se zdi - odmeva še danes. Prav njegova vloga v oblikovanju in razvoju tega gibanja bo v središču zanimanja pričujočega prispevka.

Zagonetnost Foersterjeve vloge v slovenski glasbi 19. stoletja še stopnjuje dejstvo, da v javnost po pravilu ni stopal s pisano besedo, temveč le s svojim glasbenim delom. Do danes smo lahko o njegovih namenih, nazorih in sodbah sklepali po redkih, večinoma nepodpisanih ocenah del drugih skladateljev, repertoarju ansamblov, ki jih je vodil, in glasbenih izdajah, katerih urednik je bil. Do danes smo pogrešali vir, skozi katerega bi nam Foerster spregovoril bolj neposredno, neobremenjen z grožnjo, ki so jo zanj predstavljali glasbena nerazgledanost, lažni patriotizem, provincializem in drobnjakarska zavist, tako značilna za polizobraženske elite utesnjenih in od velikega sveta nekoliko odmaknjenih kulturnih razmer. Verjetno edini približek je znani intervju, ki ga je v serijo portretov znamenitih Slovencev Obiski uvrstil Izidor Cankar. ${ }^{1}$ Pa vendar je zapis leta 1911 nastajal v času, ko nasprotja niso bila več tako živa in ko je cecilijanska reforma deloma dosegla svoj cilj, deloma pa izgubila svojo ost in estetsko ekskluzivnost. V popolnoma drugačnem zgodovinskem trenutku nastali intervju predstavlja prej oddaljen odmev nekdanjih pretresov, kot živ odsev dogajanja v prvih dveh desetletjih cecilijanskega gibanja na Slovenskem.

Tak vir bi morali iskati v popolnoma zasebni sferi, ali pa bi morda lahko nastal kot rezultat stikov z osebami, ki niso bile tako ali drugače povezane s kulturnim življenjem na Slovenskem. Že od začetkov opazovanja Foersterjevega življenja in dela se je postavljalo vprašanje o njegovem razmerju do nemškega cecilijanstva nasploh, oz. konkretneje do Splošnega nemškega cecilijinega društva (Allgemeiner Deutscher Cäcilien-Verein - ACV). Morebitna korespondenca z vodstvom društva, ki ga je do svoje smrti leta 1888 utelešal in vodil Franz Xaver Witt, bi lahko pomembno osvetlila tako podrobnosti o stopnji vpletenosti nemškega cecilijanstva v reformo cerkvene glasbe na Slovenskem, kot tudi iz prve roke pričala o Foersterjevih cerkvenoglasbenih nazorih.

Prav ta vir se je odprl v zadnjih letih s projektom ureditve in katalogizacije prek 10.000 pisem obsegajoče Wittove korespondence, ki jo hrani Osrednja škofijska knjižnica v Regensburgu. ${ }^{2}$ Med obsežnim gradivom je - po dosedanjem pregledu - 24 pisem in dopisnic pomembnih osebnosti slovenske cerkvene glasbe druge pol. 19. stoletja. Naj-

Izidor Cankar. 'Obiski. V. Anton Foerster.' Dom in svet 24 (1911), 194-196.

Foersterjevo korespondenco je v okviru raziskovalnega dela za diplomsko nalogo v knjižnici izsledila gdč. Lea Vidic, ki mi je prijazno posredovala tudi reprodukcije Foersterjevih pisem, za kar se ji na tem mestu lepo zahvaljujem. 
obsežnejši del, 11 pisem je izpod peresa Antona Foersterja. Časovni razpon ohranjene korespondence med Wittom in Foersterjem sega od prvega pisma iz leta 1874 do junija 1887, torej dobrega leta pred Wittovo smrtjo (1888). Korespondenca je v nakazanem obdobju potekala z različno intenziteto. V letih 1878 in 1885 je Foerster v pol leta odposlal tri pisma, leta 1880 v pol leta dve, v letih 1874, 1882 in 1887 pa le po eno. Iz vsebine pisem lahko sklepamo, da je bila intenziteta dopisovanja odvisna predvsem od položaja reformnih prizadevanj in se je stopnjevala predvsem v obdobjih, ko si je Foerster od Witta obetal medijske in strokovne podpore. ${ }^{3}$

Ohranjeno gradivo pa skoraj zanesljivo ne predstavlja vse korespondence med Foersterjem in Wittom. Dve pismi sta le delno ohranjeni (FoersterA 18??-02, FoersterA 18??-01). V obeh primerih manjkajo zadnje strani pisma, tako da jih urejevalci kataloga niso mogli z gotovostjo datirati. Glede na vsebino lahko sklepamo, da je moralo prvo (FoersterA 18??-02) nastati ob koncu 1877 ali v začetku leta 1878, saj Foerster v njem omenja nekaj podatkov, ki omogočajo grobo datacijo (celih deset let svojega delovanja v ljubljanski stolnici (1868-78), ustanovitev Cecilijinega društva za Ljubljansko škofijo in njegove orglarske šole kot izvršeni dejstvi).

Spet druga pisma z gotovostjo manjkajo. Musica sacra, glasilo Splošnega nemškega cecilijinega društva, je leta 1876 objavila Foersterjev dopis, v katerem opisuje v ljubljanski stolnici izvajani reperotar. ${ }^{4}$ Med ohranjenim gradivom lahko najdemo podoben dopis iz leta 1878, ki ima enako strukturo in namen ter v katerega je Witt vnesel vrsto uredniških popravkov namenjenih prilagoditvi besedila za objavo v Musica sacra, tako da lahko skoraj z gotovostjo sklepamo, da se izvirni dopis za leto 1876, ki je bil najverjetneje prav tako naslovljen na Witta kot urednika revije, ni ohranil. Prav pogoste Wittove lastnoročne opombe - ki se nedvoumno nanašajo na možnost objave celotnih pisem ali odlomkov iz njih - kažejo, da gre verjetno za tisti del korespondence vodje ACV, ki je bil povezan z njegovim uredniškim delom in izhajanjem revije Musica sacra. Praktično v vseh pismih najdemo vsaj eno od treh vsebinskih enot, povezanih z revijo. Najmanj je poročil o stanju cecilijanskega gibanja na Slovenskem (FoersterA 1878.05/12, FoersterA 18??-02). V petih pismih (FoersterA 1874.07.29, FoersterA 1880.01.30, FoersterA 1885.03.29, FoersterA 1885.07.24, FoersterA 1887.06.12) ponuja Foerster svoja dela v oceno Wittu, oz. ga prosi, da jih posreduje drugim recenzentom, seveda z namenom, da bi bila ocena objavljena v osrednji cecilijanski reviji. V preostalih petih (FoersterA 1878.07.10, FoersterA 1880.01.30, FoersterA 1880.06.24, FoersterA 1882.01.11, FoersterA 18??-01) pa prosi za mnenje o delih drugih slovenskih skladateljev, večinoma z namenom, da bi trdneje in na neodvisni avtoriteti utemeljil svoje odklonilno mnenje o njih. Ta tesna povezanost vseh pisem z revijo Musica sacra nas utrjuje v prepričanju, da gre dejansko za korespondenco uredništva in ne Wittovo zasebno korespondenco. O morebitnih zasebnih pisnih stikih med Foersterjem in Wittom iz ohranjenega gradiva ne moremo sklepati.

Ohranjeni del Foersterjevega dopisovanja z Wittom prinaša nekaj pomembnih informacij, ki dodatno osvetljujejo vrsto ključnih dogodkov v prvem desetletju obstoja Cecilijinega društva za Ljubljansko škofijo. Ti so bili večinoma odraz razhajanj v pogledih

Podroben katalog korespondence Fr. X. Witta bo izšel predvidoma leta 2007 v okviru zbirke Kataloge bayerischer Musiksammlungen. Zv. 14/13-14. Ur. D. Haberl.

Anton Foerster. 'Aufführungen des Domchores zu Laibach in Krain (Österreich): seit Juli 1868 bis August 1876.' Musica sacra $9.11(1876), 101-102$. 
na nadaljnjo pot reforme cerkvene glasbe, ki so se vse od ustanovitve društva kazala znotraj cerkvenih ustanov. Na eni strani je stala majhna skupina radikalnih cecilijancev, ki so želeli takojšnjo reformo v smislu natančnega upoštevanja cerkvene liturgične zakonodaje, kar bi pomenilo predvsem prenehanje uporabe glasbe z besedilom v ljudskem jeziku (slovenskim, nemškim ali italijanskim) pri petih mašah in blagoslovu z Najsvetejšim, prečiščenje repertoarja po cecilijanskih merilih in - to so zagovarjali le najbolj zagreti - odstranitev pevk s korov. Na drugi strani pa je bila večina duhovščine, del članstva cecilijijnega društva in pretežni del javnosti, ki so zagovarjali postopnost pri uvajanju sprememb in sprejemala delo Gregorja Riharja kot ustrezno osnovo za nadaljevanje reforme.

Prav vprašanje vrednotenja skladateljske zapuščine Gregorja Riharja je postalo v letih med 1877 in 1890 torišče spopada med obema smerema. O Foersterjevem odnosu do Riharjeve glasbe do danes nismo imeli enoznačnih informacij. Na eni strani je bilo izrivanje Riharjevih skladb iz repertoarja eden od osrednjih očitkov Foersterjevih nasprotnikov. Na drugi strani pa je Foerster precejšnje število Riharjevih melodij vključil v osrednjo cecilijansko pesmarico Cecilija..$^{5}$ Izšle so sicer nekoliko popravljene in s spremenjeno harmonizacijo, vendar so bile te spremembe predvsem posledica dejanskih kompozicijskih slabosti Riharjevih izvirnikov in le v manjši meri poskus podreditve cecilijanskim stilnim idealom. V korespondenci z Wittom so Foersterjeve izjave o kvaliteti Riharjeve glasbe povsem enoznačne. V pismu s konca leta 1877 ali začetka 1878 (FoersterA 18??-02) opisuje razmere v cerkveni glasbi na Slovenskem in jih utemelji s trditvijo: „Dazu ist ein Geschmack zu läutere, den wir dem sel. Geistlichen Gregor Rihar (meinem Vorgänger), dem Abgott der Tonkunst beim Volke und der älteren Geistlichkeit, zu danken haben. Als Beleg dafür bin ich so frei von den Hunderten solcher Schundlieder bloß etwas beizugeben. ${ }^{6} \mathrm{~V}$ naslednjem pismu iz julija 1878 je Foerster še enkrat apeliral na Witta in ga prosil za obsodbo Riharjevih skladb, s katero je želel podkrepiti lastno avtoriteto in osmešiti nasprotnike (eden od Riharjevih privržencev naj bi celo sprejemal stave, da se bo Witt pohvalno izrazil o Riharjevih skladbah). ${ }^{7}$

Odnos do Riharjeve glasbe je bil tudi povod za verjetno najsilovitejšo časopisno polemiko cecilijanskega časa, katere predmet je bila prav reformirana cerkvena glasba v ljubljanski stolnici. Sprožil jo je satirični časopis Brencelj, ki ga je urejeval Jakob Alešovec. Že v jeseni leta 1879 se je lotil Antona Foerstreja. Sprva le z majhno bodico, češ da se ni udeležil volitev, in da s tem ni podprl slovenskih kandidatov. ${ }^{8} \mathrm{~V}$ sklepnih številkah letnika pa je v kratko prigodo Rešpehtarjove kuharce nanizal celo vrsto očitkov, ki so bili skoraj v celoti naravnani na Foersterjevo osebo, ne pa na njegovo delo. Tako mu očita, da v družinskem krogu govorijo nemško, da je skop, nedružaben, da kot glasbeni učitelj slabo poučuje in skrajšuje ure, da je član čitalnice le zato, da zastonj bere domače in tuje časopise, da ne voli Slovencev, da se ne pokropi z blagoslovljeno vodo, ko stopi v cerkev, itd. Pisec pa se dotakne tudi njegovega glasbenega delovanja.

\footnotetext{
Anton Foerster. Cecilija. 2 zv. Celovec: Družba sv. Mohorja, 1883-1884.

"Ob tem moramo očistiti okus, za katerega se imamo zahvaliti pokojnemu duhovniku Gregorju Riharju (mojemu predhodniku), glasbenemu maliku ljudstva in starejše duhovščine. V dokaz sem tako prost, da Vam pošiljam le nekaj izmed stotin teh pogrošnih pesmi.*

FoersterA 1878.07.10.

Brencelj 11.14 (1879).
} 
Tako je mnenja, da tudi Foersterjeva glasbeniška usposobljenost ni tako izredna, češ da je vsaj 16 slovenskih glasbenikov boljših od njega, pa so vsi brez službe. Avtor natrese tudi nekaj kritičnih opazk o njegovem delu, iz katerih veje mnenje javnosti, predvsem pa duhovščine tistega časa o cecilijanski glasbi. Le-ta naj bi bila žalobna in obupana, celo husitska in luteranska. Da izraža zapis predvsem stališča duhovščine, kaže avtorjeva skrb, da bodo zaradi cecilijanskega petja ljudje še manj hodili v cerkev. ${ }^{9}$ Brencljevo ukvarjanje s Foersterjem zaokroža še nekaj manjših šal in zabavljivih pesnitev v drugi in šesti številki istega letnika.

Na odgovor v anonimno objavljenem dopisu Poslano - Vobrambo pravega cerkvenega petja in g. Försterja, ${ }^{10}$ katerega avtor je bil Jakob Aljaž in v katerem je nanizal vrsto stvarnih argumentov proti Brencljevim obtožbam, se je vsul pravi plaz polemičnih odmevov. Brencelj je v naslednji številki objavil prizor Z Olimpa, ${ }^{11} \mathrm{v}$ katerem preminuli veliki možje slovenske kulture v nebesih obsojajo cecilijansko petje. V humorno pripovedovanje je vpletenih tudi nekaj novih stališč, mdr. da je cecilijansko prizadevanje za višjo umetniško raven cerkvene glasbe le želja po razkazovanju izvajalskih sposobnosti in nastopaštvo. Sestavek se pohujšuje nad objavami programov in imen izvajalcev cerkvene glasbe, ki jih je ob posebnih priložnostih prinašal Laibacher Zeitung. Na Aljažev anonimni dopis je Alešovec, misleč da je Foersterjev, ${ }^{12}$ odgovoril tudi v Slovencu. ${ }^{13}$ Njegov zapis ne prinaša nobenih argumentov, le dodatne izbruhe bojevitega nacionalizma, ki mejijo na zagrizeni šovinizem. Tako pravi, da imamo Slovenci svojo glasbo in svoje skladatelje, Foerster naj pa kar Čehe odrešuje. S svojim laskanjem Cecilijinemu društvu, ki naj bi imelo plemenit namen, je hotel nasprotnike razdeliti, Foersterju pa omajati oporo, ki jo je imel v društvu. Njegovo stališče je v Slovencu podprla še cela vrsta dopisnikov, večinoma duhovnikov iz različnih delov škofije, Foersterja pa ob Jakobu Aljažu le še ortodoksni cecilijanec Miroslav Tomec ${ }^{14}$ in tajnik cecilijinega društva in urednik Cerkvenega glasbenika Janez Gnjezda. ${ }^{15}$

O dogajanju je Foerster Wittu poročal takole: "Gerade wird bei uns in Krain ein heftiger Streit gefächet; von dem "vielgerühmten" laibacher Klerus hat ein Teil, dem lasuiven Riharianismus immerdar huldigend, gegen meinen Reformbestrebungen abermals, schon zum X-ten Male, Front genommen, bedauerlich jedoch mit gemeinen Haßton; gemietet ist ein slow. Hitzblatt, in welchen die gröbsten und unlautersten Ehrenbeleidigungen auf mein Haupt geschleudert wurden. Auf eine mannhafte Verteidigung von Seite eines wackeren Geistligen wird nicht minder wieder gemein geantwortet in einem klerik. polit. Blatt (slov.). Würde ich nicht überzeugt sein, dass unsern heiligen Sache dennoch vollständig singen muß, und wäre nicht ein beträchtlicher Teil der Geistlichkeit standhaft hinter mir, wahrlich ich verlöre nicht den Mut, in Cäcilianis weiter zu arbeiten, dass wohl nicht, aber dem hiesigen Vereine würde ich "Vale« sagen

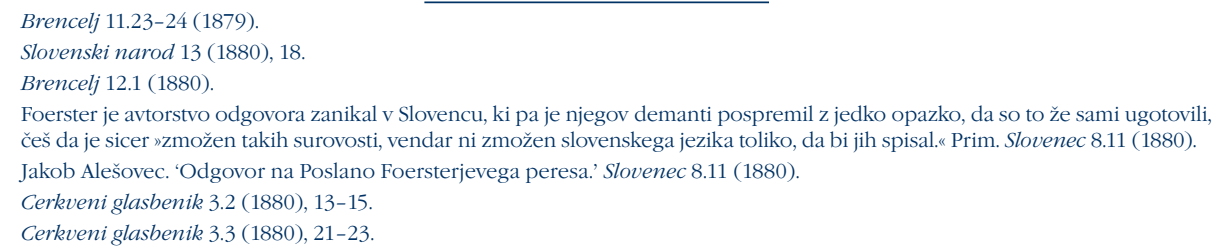


und würde nicht mit Perlen so herumwerfen. Gott gebe, dass es doch bald dazu käme: "Per angusta ad augusta."Zuletzt bitte ich, euer Hochwürden, vielmals um Entschuldigung, das ich Ihrer die teueren Zeit durch diese unerquicklichen Vorkommnisse verkürze, ich habe darin doch eine Erleichterung zu finden angestrebt. Die Gemüter sind hier furchtbar aufgeregt! «16

Razburjeni duhovi so močno vplivali tudi na delovanje Cecilijinega društva za Ljubljansko škofijo in vsebino Cerkvenega glasbenika. Članstvo v društvu začne po silovitem vzponu v letih 1877-1879 postopno padati, uredništvo društvenega glasila pa je moralo očitno iskati srednjo pot med obema strankama v društvu. Položaj lahko lepo osvetlimo še z enim primerom, ki kaže, kako vsaksebi je bilo v presojanju cerkvene glasbe članstvo Cecilijinega društva za Ljubljansko škofijo. Leta 1879, prav v času Brencljevega napada na Foersterja je v Ljubljani izšla Missa sancti Joannis, Roberta Burgarella. Cerkveni glasbenik je v zadnji številki letnika skladbo priporočil kot delo, iz katerega "veje cerkveni duh «. ${ }^{17}$ Do sedaj smo glasbeni zgodovinarji - resda brez posebne osnove v virih - domnevali, da so ocene v oglasniku v celoti ali vsaj pretežno prihajale izpod peresa Antona Foersterja, ki je bil med sodelavci Cerkvenega glasbenika edini tudi strokovno usposobljen za to delo. To v primeru Burgarellove maše očitno ne drži, saj je njegovo, v pismu Wittu izraženo mnenje o skladbi, diametralno nasprotje objavljenega v Cerkvenem glasbeniku. V pismu iz junija 1880 piše: »Mit der Kritik der Burgarell'schen Messe haben Sie unserer Sache einen guten Dienst erwiesen, man muß die Keckheit ein wenig einschüchtern und auf Blösen ein Pflaster geben, wenn man mit gewissen Leuten einen modus vivendi eingehen will. «18 Odlomek iz pisma se nanaša na oceno maše, ki je izšla v Musica sacra. Skladbo je kritik (verjetno Witt) označil za značilni primer lidertaflovskega sloga, ki lahko le na Kranjskem ali Italiji velja za primerno cerkveno glasbo, sicer pa ne. ${ }^{19}$

Tudi dobro leto kasneje je Foerster v Wittovi avtoriteti iskal podpore za svoja stališča do del drugih slovenskih skladateljev. "Wie überall, so gibt es auch in Krain, und dies in noch größerer Anzahl, seichte Musiker, die die Pläne der Cäciliäner durchkreuzen und aus Ehrgeiz, daß sie nicht die erste Rolle spielen, dem Verein Prügel unter die Füße werfen. Ich habe mir angemaßt, unter den 26 Tantum ergo's die am Schluße des Heftes die bezeichneten Nummern als die schwächsten des Heftes zu bezeichnen, die Originalien des Pater Ang. Hribar sogar lobend hervorgehoben (natürlich im Ganzen.) Darob wird gegen uns wahre Anhänger nicht würdig agitiert. Ich bitte darum inständigst im Interesse der heiligen Sache, Hochgeehrte Herr Generalpräses zu geruhen nur privatim (bitte nichts abdrucken zu lassen - vorläufig) auf einer Karte Ihre maßgebende Meinung über

16 „Pri nas na Kranjskem se pravkar bije silen spopad; del 'preslavne' ljubljanske duhovščine, ki še vedno časti opolzko riharjanstvo, se je ponovno, že X-tič podal v boj proti mojim reformnim poskusom, vendar na žalost v tonu nizkotne sovražnosti; najeli so slovenski satirični časopis, ki mi sedaj v obraz meče najbolj neotesane in nepoštene žalitve. Na možato obrambo s strani nekega vrlega duhovnika je sledil nič manj nizkoten odgovor v klerikalnem političnem dnevniku (slov.). Če ne bi bil prepričan, da se moram celoti posvetiti naši sveti stvari in bi ne imel stanovitno za seboj znatnega dela duhovščine, res, ne izgubljam poguma za cecilijansko delovanje, to ne, a tukajšnjemu društvu bi rekel 'Vale' in ne bi več tako razmetaval z biseri. Bog daj, da bi kmalu obveljalo 'Per angusta ad augusta.' Na koncu Vas, Prečastiti, prosim večkrat odpuščanja, da Vam krajšam dragoceni čas s temu nespodbudnimi dogodki, a v tem sem iskal vsaj nekaj olajšanja. Duhovi so tu strašno razburjeni!«

17 Oglasnik.' Cerkveni glasbenik 2.12 (1879), 100.

18 „S kritiko Burgarellove maše ste naši stvari naredili veliko uslugo. Predrznost je potrebno zastrašiti, odprte rane pa obvezati, če hočemo z nekaterimi ljudmi najti modus vivendi."

19 'Burgarell: Missa s. Joanis, op. 10.' Musica sacra 13.6 (1880), 71. 
die Sammlung, die ich unter Kreuzbend sende, anzugeben." (Foerster A 1882.01.11). Javno polemiko je namreč sprožila njegova ocena zbirke 26 Tantum ergo, v kateri je p. Angelik Hribar ob delih drugih skladateljev izdal tudi 12 svojih skladb. Čeprav je Foerster v Cerkvenem glasbeniku zbirko v celoti ocenil zelo pozitivno, je njegove nasprotnike zbodlo dejstvo, da je nekatere Hribarjeve skladbe med vrsticami označil kot šibkejše. ${ }^{20}$ Odzval se je Fran Hlavka v Ljubljanskem zvonu. ${ }^{21}$ Oceno Hribarjeve zbirke je izrabil za ponoven napad na radikalne cecilijance in poskušal gibanje razdeliti s tem, da je p. Angelika Hribarja postavil na čelo druge smeri v slovenskem cecilijanstvu, ki se zavzema za postopno uvajanje dostojnejše cerkvene glasbe, ter vztraja pri ohranjanju slovenščine v obredih tudi tam, kjer je cerkveni predpisi ne dovoljujejo. Javno je Foersterja in Cecilijino društvo z odgovorom podprl le Hugolin Sattner, ki je zavrnil večino Hlavkovih navedb. ${ }^{22}$

Do razhajanj med vodilnimi osebnostmi cecilijanskega gibanja na Slovenskem je prihajalo tudi kasneje. Eno takih, doslej skritih nesoglasij nam zopet razkriva šele Foersterjeva korespondenca z Wittom. Sprožil ga je izid maše Pobožni vzdihi Avgusta Armina Lebana, ki jo je leta 1885 posthumno izdal njegov brat Janko Leban. Delo ob nastanku 20-letnega skladatelja je v prvih letih svojega obstoja nagradila Glasbena matica, njegovo glasbeno vrednost pa je pred izidom aprobirala vrsta uglednih domačih in tujih glasbenikov. Izdajo je zelo ugodno ocenil Danilo Fajgelj v Ljubljanskem zvonu. ${ }^{23}$ Okoliščine izdaje in velika skrbnost, s katero je Janko Leban pripravil izdajo skladbe, kažeta na to, da se je želel izdajatelj zavarovati pred ostrimi kritikami s strani strogih cecilijancev. Za slovensko kulturno okolje časa zelo nevarna zmes tujih avtoritet, domačega zmernega cecilijanca in oživljanja nasprotovanj med Cecilijinim društvom in Glasbeno matico je obetala ponoven javni konflikt. Cerkveni glasbenik se na izid zbirke in kritiko v Ljubljanskem zvonu ni odzval. Razloge za to lahko razberemo iz Foersterjevega pisma z dne 29.3.1885 (FoersterA 1885.03.29) »Für die Abfertigung der Zudringlichkeit des Leban'schen Schmierwerkes wissen Ihnen, hochgeehrter Herr Redakteur, alle hiesigen Cäcilianer der besten dank; hindurch ist unserer Sache viel genützt und die seichten Ultras sind eingeschüchtert worden. Das, resp. der, Cerkveni Glasbenik, ist das »Opus 1." nicht einmal zugeschickt worden aus furcht, daß wir über dasselbe herfallen würden. Man hoffte von Euer Hochwürden wenigstens hier und da ein milderes Urtheil, um es dann gegen uns aus spielen zu können. Also nochmals unseren Dank für die Aufmerksamkeit, welche Sie, hochgeehrter Herr Canonicus, unserer Verhältnissen von Zeit zu Zeit zu schenken die Güte haben. "(Foersterjevo besedilo dopolnjuje še Wittova lastnoročna opomba, da je uredništvo prejelo še dve podobni zahvali za objavljeno kritiko Lebanove skladbe.) Molk Cerkvenega glasbenika ni bil posledica strahu pred razgaljanjem notranjih nesoglasij med vodilnimi osebnostmi cecilijanskega gibanja (v tem primeru Foerster-Fajgelj), temveč skrbno načrtovanega poskusa zmernejše smeri v gibanju, da bi z ugodno oceno v nemškem časopisju in avtoriteto tujih ugladnih glasbenikov omajala Foersterjev položaj nesporne slovenske avtoritete v presojanju cerkvene glasbe. Poskus pa je bil, kot smo videli neuspešen. Še več, dosegel je svoje nasprotje

\footnotetext{
20 Cerkveni glasbenik 4.11 (1881), 88.

21 Fran Hlavka. 'Slovenske muzikalije.' Ljubljanski zvon 2.1-2 (1882), 58-60, 120-121.

22 p. Hugolin Sattner. 'Resnici na ljubo.' Cerkveni glasbenik 5.2 (1882), 10-12.

23 Danilo Fajgelj. 'Nove muzikalije.' Ljubljanski zvon 5.5 (1885), 307-311.
} 
(odtod tudi čestitke uredništvu). V Musica sacra objavljena kritika je bila uničujoča in je še okrepila Foerstrerjevo avtoriteto.

Novoodkrita korespondenca z Wittom nam brez dvoma pove veliko novega o začetkih cecilijanskega gibanja na Slovenskem in vlogi Antona Foersterja v njem. Če se je slovenskemu glasbenemu zgodovinopisju do sedaj cecilijansko gibanje zdelo enotno, se nam v luči novih dejstev veliko bolj plastično zarisujejo razpoke, ki smo jih poprej le slutili. Cecilijino društvo za Ljubljansko škofijo je bilo konglomerat smeri in osebnih nazorov, ki so segali od prepričanja, da je njegov namen predvsem izboljšati kvaliteto izvajanja cerkvene glasbe, do druge skrajnosti, ki jo predstavlja Foerster s svojim v pismih izpričanim ortodoksnim cecilijanstvom. Navidezna enotnost, ki nas je desetletja zavajala, je predvsem zasluga skrbne uredniške politike Janeza Gnjezde, ki je z društvenim glasilom krmaril med Scilo in Karibdo cecilijanske vneme ter občutljivostjo dela članstva in slovenske javnosti.

Novi viri pa zahtevajo tudi drugačno opredelitev Foersterjevih nazorov o cerkveni glasbi. Če smo poprej iz znanih dejstev sklepali, da je bil prav on idejni vodja cecilijanskega gibanja na Slovenskem, zbuja ohranjena korespondenca z Wittom dvom v upravičenost te domneve. V njej izraženi nazori, predvsem pa izredna ostrina pri izražanju odnosa do konkretnih vprašanj in posameznikov, precej odstopa od idejne osnove in načina dela, značilnega za delovanje Cecilijinega društva za Ljubljansko škofijo. Radikalno in brezkompromisno zavračanje Riharjevega opusa, nasprotovanje pretežnemu delu sodobne slovenske domače produkcije ter podcenjujoč odnos do velikega dela članstva v Cecilijinem društvu nas silijo v to, da reinterpretiramo mnoga dejstva povezana s Foersterjevim cerkvenoglasbenim delovanjem. Skeptik bi seveda lahko pomislil, da je bil Foerster v svojih pismih neiskren, bodisi zato, da bi ugajal Wittu - katerega nazore je seveda poznal - in svojim skladbam utrl pot na nemško tržišče (osnovo za tako tezo bi lahko našli tudi v korespondenci), bodisi zato, da bi si pridobil zaveznika za utrditev svojega položaja vodje cecilijanskega gibanja na Slovenskem.

Pa vendar vsebina pisem preveč dosledno pojasnjuje vrsto doslej nerazumljivih protislovij v razvoju cecilianskega gibanja, da bi jo lahko razumeli le kot manipulacijo posameznika s tujo avtoriteto, ki ji je bil vpogled v realno stanje cerkvene glasbe na Slovenskem zaradi jezikovnih pregrad v veliki meri onemogočen. Protislovje med javnimi očitki Foersterju, da iz repertoarja izključuje riharjanske skladbe in podobo pesmarice Cecilija, katere urednik je bil, sorazmerno majhen delež sodobne slovenske produkcije v repertoarju ljubljanske stolnice in njena zastopanost v prilogah Cerkvenega glasbenika, ki ga je urejal, nenazadnje pa tudi njegova zadržanost pri javnem izražanju mnenj o cerkveni glasbi, ki so bila očitno do te mere radikalna, da so bila za slovensko javnost - in vanjo lahko vključimo tudi večino članov Cecilijinega društva za Ljubljansko škofijo - popolnoma nesprejemljiva; vse to priča o tem, da je bil Foerster s svojim strokovnim znanjem sicer nepogrešljiva opora cecilijanskega gibanja na Slovenskem, vendar ni bil tisti, ki je s prilagajanjem univerzalnih nazorov nemškega cecilijanskega gibanja slovenskim razmeram izoblikoval idejno podlago za delovanje slovenskega cecilijanstva. Ključne osebnosti tega procesa moramo verjetno iskati krogu stolniških duhovnikov, ki so, očitno bolj kot je to moč razbrati iz virov, v ozadju narekovali cerkvenoglasbeno delo. 